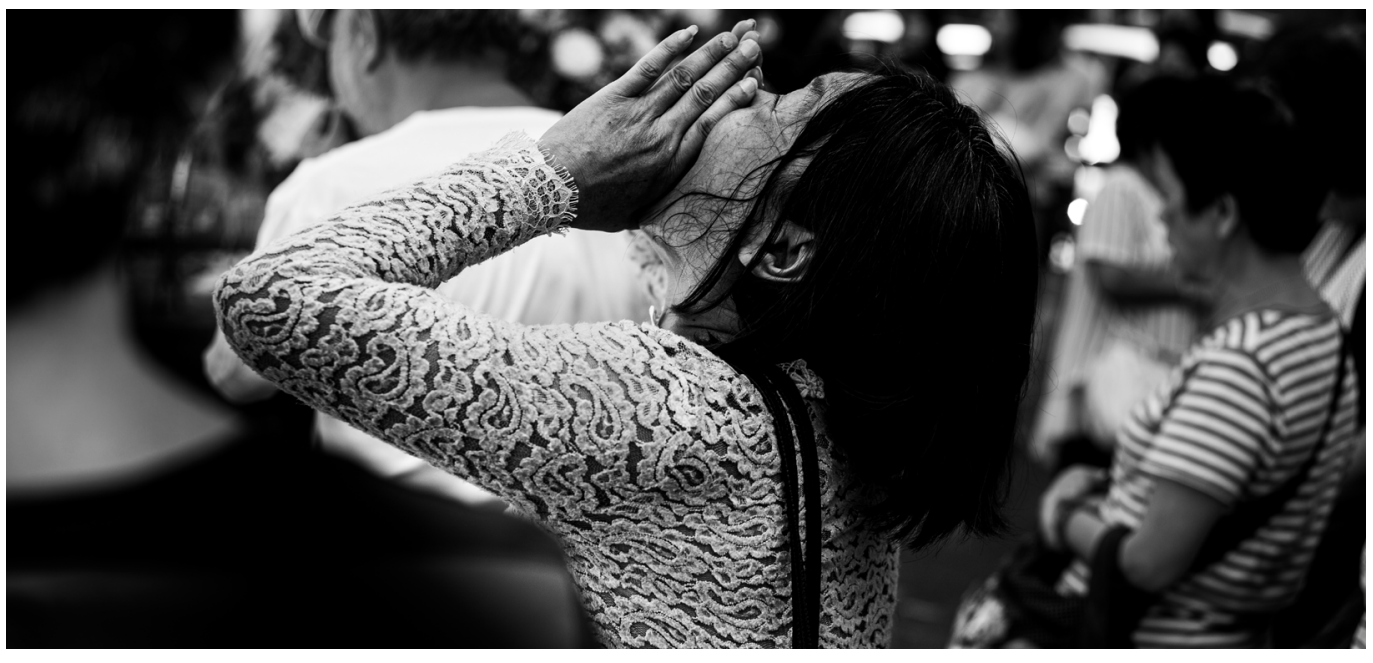

Hong Kong Protests.

PC: Jonathan van Smit (CC).

\title{
A Feminist Snap Has Feminism in Hong Kong Been Defeated?
}

\author{
Petula Sik Ying HO \\ Minnie Ming LI
}

This essay analyses the politics of the Hong Kong protest movement and the displacement of feminism within it. It highlights the emergence of an internal rift between 'Left in form, Right in essence' (形左實右) feminists and 'Leftard' (左膠) feminists (those who refuse to move to the Right), which, along with the suppression of dissent within the protest movement, ultimately led to the collapse of Hong Kong feminism.

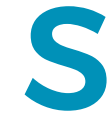
ince the beginning of the Anti-Extradition Law Amendment Bill protest movement in Hong Kong in 2019, the question 'Where were Hong Kong's feminists?' (女權撚去咗邊) has been raised intermittently on Hong Kong social media. In this Cantonese expression, the character 撚 refers to male genitalia and is used as an expression of contempt, akin to the English word 'fucking'. As women were subjected to police brutality, mainstream voices in the protest movement began to ask: "Where did the fucking feminists go? Why are you feminists not doing your part?' In this essay, we review the structure of the Hong Kong protest movement and the dislocations of the feminist movement within it, highlighting the emergence of an internal rift between 'Left in form, Right in essence' (形左實右) feminists and 'Leftard' (左膠) feminists (those who refuse to move to the Right), which ultimately led to the collapse of Hong Kong feminism. 


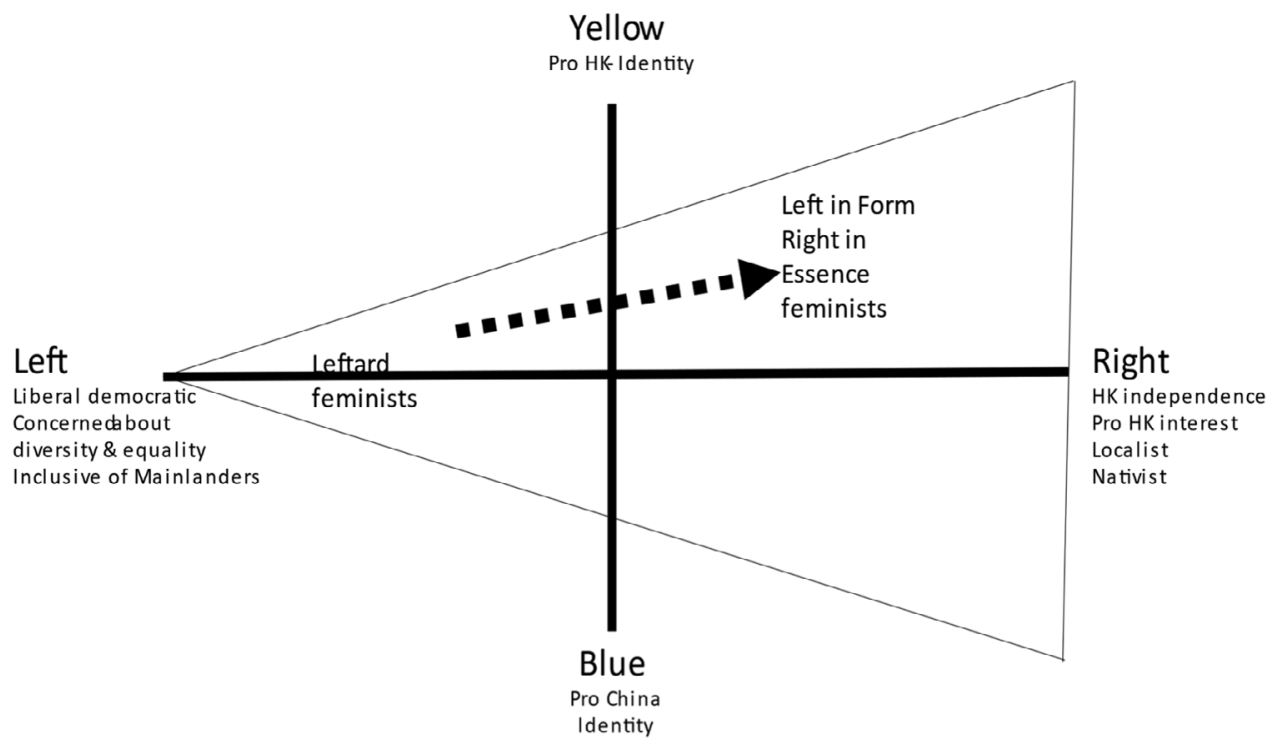

Red

(CCP)

\section{Visualising Hong Kong Feminism}

Even though it obviously oversimplifies the composition of the broader protest movement, Diagram 1 helps us understand the complexities of Hong Kong's feminist landscape. The two axes-the $\mathrm{x}$ axis representing the range between 'Left' and 'Right' and the y axis showing that between 'Yellow' (pro-local Hong Kong identity) and 'Blue/Red' (pro-China and pro-Chinese Communist Party, respectively) positions-define four possible political stances. It is important to note, however, that the Left/Right and Yellow/Blue-Red variations should not be seen as mutually exclusive dichotomies, but rather as a continuum. Not only are the binary opposites not unitary categories; they also are generally used to define each other.

In general, the Left is seen as more liberal democratic as it is inclusive of mainlanders, concerned about diversity and inequality, and supportive of more welfare and services for disadvantaged communities. The Right is seen as more focused on Hong Kong's specific interests, with the most extreme fringes advocating independence for Hong Kong. They are also called localists or nativists as they campaign for a Hong Kong exclusively for Hongkongers, which does not include mainland Chinese. In relation to the 2019 protests, the Yellow ribbons have been supportive of the movement, are against the Extradition Law Amendment Bill (ELAB), and are ostensibly democratic. The Blue ribbons, instead, have been pro-China and have supported the ELAB. The 'Bluest' among them can also be described as 'Red' because of their support for the Chinese Communist Party (CCP).

Specifically, Diagram 1 purports to show the conflict within the Yellow-Left quarters between two groups of feminists-whom we have called the 'Left in form, Right in essence' feminists and the 'Leftard' feminists. While the latter remain staunchly anchored in the Yellow-Leftist quarter, the former have chosen pro-localism/nativism over feminist principles, shifting to the YellowRight quarter.

In a recent article, we took this conflict as our starting point to declare 'the defeat of Hong Kong feminism' (香港女權的敗北) ( $\mathrm{Li}$ and Ho forthcoming). Our argument was that Hong Kong 
feminism was defeated not because we chose the losing side, but because of the self-inflicted injury of selling our souls, forgetting our mission, and abandoning our ethics of care. Our defeat occurred because the feminist movement jumped on the bandwagon of the mainstream anti-ELAB movement, thinking it was a good political bet to gain credibility and expand our influence. This motivation resulted in a self-silencing with respect to the violent tactics deployed both by and within the protest movement, which ultimately led to what we argue is a substantial defeat for Hong Kong feminism. It is a self-inflicted injury as it is a situation brought on by us, by our own actions, or our failure to act.

With this declaration, we aim to question why the current suppression of feminism, especially our self-inflicted injuries, cannot be seen more clearly. How has it come to this? If becoming conscious and refusing to surrender our agency are forms of feminist struggle, are we not behaving like fools if we attempt to cover up the mistakes we have committed along the way? What has made it impossible for us to confront the feminist defeat and go as far as to conceal it? We believe we have been seeing the world through 'Yellow-coloured glasses' and that a change of lens is in order. For this purpose, we need to create a new discourse through which we can interpret reality.

Since 2019, we have been coining new terms with a view to revealing some hidden forces of oppression, so we can make sense of how we have become an oppressing force ourselves. We believe transformation can only come from self-criticism and the renewal of the self. If feminism seeks to transform patriarchy, gender relations, and society, we should not exclude self-criticisms and should be aware of the violence of our own practices of bordering-that is, maintaining boundaries that exclude and oppress others. What we feminists really need to do is to not respond too quickly when someone asks us: 'Where the fuck have you feminists gone?' Rather, we should ask ourselves where has the feminist perspective gone in our attempt to prove ourselves as loyal Hongkongersan identity that has come to subsume everything else.
One might wonder what the point is of declaring the defeat of feminism in the context of the loss of the Hong Kong protest movement? What is there to be gained by doing this? Our assertions do not come from arrogance, moral superiority, or greater knowledge. They come from our belief in the importance of reflecting on our life pathways and experiences and in the wisdom of relinquishing false hope and cruel optimism to open an intellectual space for new ideas to emerge (Berlant 2011). We view this as creating an 'epistemic break' (Ho et al. 2018: 969) or as a 'feminist snap' (Ahmed 2017: 187)-that is, a wake-up call.

\section{Why Can't We See Our Defeat?}

The first step to create this 'epistemic break' is to understand why we are unable to see our defeat. We believe there are three reasons for this selective blindness.

First, some 'Left in form, Right in essence' feminists still believe the feminist movement has gained strength through the Hong Kong protest movement, and that we won the bet. They feel the protests featured a few glorious moments, such as the 'Hong Kong Mothers' Anti-Extradition Rally' of 14 June and 5 July 2019, initiated by several feminist academics, and the 'Anti-ELAB \#MeToo Rally' of 28 August 2019, initiated by the Association Concerning Sexual Violence Against Women. Back then, most feminists did not question the populist mythology of the mainstream discourse of the movement, or its exclusionary practices, but were satisfied with the movement's instrumental and superficial inclusion of feminism. They hoped feminism would gain momentum and expand its influence by riding on the mobilisation, especially when they noted the increase in popular support for the protests. However, those glorious moments were short-lived and their success only illusory. In our opinion, we cannot be proud of such success if it comes from endorsing physical violence against the police and those who are opposed to the movement, who are seen as deserving of attack and unworthy of our sympathy. 
The feminist movement, as well as the broader protest movement, cannot succeed unless people are made aware of how Hong Kong's struggles relate to women's rights-and, in fact, to intersectional inequalities of all types. This may require a new consciousness that goes beyond playing into a traditional patriarchal framework to earn some credibility to speak up. Some feminists did not make the connection between fighting on the frontline and fighting for women's rights. When they shouted slogans, they were not thinking about women's rights. These feminists thought only women who were completely loyal to the movement deserved sympathy; their focus was not on women's rights or female voices at large. Most feminists did not harness the momentum of the pro-democracy movement to critically advocate intersectional justice and care for those who are disadvantaged because of their race, ethnicity, or disability. Those who were critical of the movement have often been seen as traitors and those who held different views as political opponents deserving to die. We posit that in their eagerness to show support to the movement and to silence alternative views-including the voices of Leftard feminists such as the two authors-feminists gave up their souls. When the movement failed, feminism perished with it.

Second, we have been too afraid to be different in the context of a populist movement. This protest movement was repeatedly described as leaderless, but it was not; it had an imaginary leader in a collective sense. It did not really matter who the leader was, as long as they were saving the 'Hong Kong people'. The task for all of us was to protect the young protesters on the frontline, and anything else was secondary. Through populist mythological narratives, the movement established a particular orthodoxy that prioritised the interests of certain protesters over others. To be accepted within the movement, one had to become a 'useful' tool for it, and anyone who did not contribute to the 'ultimate victory of the people' in the way the 'people' wanted at that moment could be singled out as guilty or kicked out as an enemy. It is in this context that feminists-consciously or unconsciously-came to ignore issues of systemic genderbased violence against women (unless perpetrated by the police), or disadvantaged communities in Hong Kong society. While these issues continued to exist, they were no longer a priority. The boundaries between righteousness and evil, the enemy and us, were constantly being redrawn; those who were on our side today may not be tomorrow. While sometimes strategically accepted into the 'us' camp, groups such as the 'Leftard' feminists and pro-movement mainlanders could be excluded at any time as not being pure and genuinely loyal. It was the danger of being defined as beyond the pale at any moment and of becoming the target of hostility that led many feminists to demonstrate in word and action an eagerness to participate in the movement even when they should have adopted a more critical approach.

Third, some of us decided we should be clever about the situation. For these people, 'Left in form, Right in essence' feminism became a survival strategy. Some feminists indiscriminately accepted populist mythologies with a view to maximise the overall utility of the movement, protecting its image, and expanding its influence. They believed feminists should pursue a theoretical vision of feminist social movements and empirical field research in the service of this goal. Elsewhere, we analysed several cases that underline these dynamics ( $\mathrm{Li}$ and Ho forthcoming). Here, we provide just two instances to orient the reader.

\section{The Kwong Wing Catering Incident}

In February 2020, when Covid-19 became increasingly severe in Hong Kong and the government was initially reluctant to close the border, the pro-movement restaurant Kwong Wing Catering openly stated that it would close its doors to all Mandarin speakers except those from Taiwan. Nearly 100 shops in Hong Kong adopted a similar policy. At that time, Minnie Li co-authored with her husband, Roger Chung, a short review published in the medical journal The Lancet in which she called for attention to the anti-Chinese sentiment in public health measures (Chung and Li 2020). Before that, the couple and a group of friends had 
visited Kwong Wing Catering intending to speak to the owner. Many netizens saw the visit as a failure to understand Hongkongers' fears about the imposition of Mandarin Chinese on the local population, as well as causing embarrassment for the restaurant staff. Li was immediately called 'mainland chick' (大陸雞), 'VaChina', 'green tea bitch' (綠茶 婊), 'corrupt academic' (學棍), and 'feminist dick' (女權L) by netizens and various opinion leaders. Her Facebook page was overwhelmed with abuse, and someone even wrote anonymously to her university department demanding her dismissal, claiming emphatically that she had misbehaved before her marriage.

It was not uncommon for women and feminists to be the targets of intense attacks within the movement. By reflecting on the anti-China character of the movement (Li 2020b, 2020c), criticising its patriarchal orientation (Ho 2019a, 2019b), and refusing to cut ties with Jon Solomon over his criticism of virologist Yuen Kwok Yung of the University of Hong Kong for some racist remarks he had made against mainland Chinese (Li 2020e), the two authors came to be among the favourite targets of the localists. Right-wing localist opinion leader Lewis Loud wrote several articles in the local press and on social media in which he called one of the authors 'a blow to the moral high ground of the movement' (Loud 2020a), 'obsessed with self-importance', a 'high-minded academic green tea', and 'an academic supporter of the Chinese colonialists' (Loud 2020c). Taking the opportunity to address all 'Left-wingers' (including feminists, of course), Loud (2020c) wrote: 'After the anti-ELAB movement, in fact, the Left-wing and the liberals, no matter how much they dislike it, have to choose whether they want to go ahead and become Minnie Li and Ho Sik Ying.'

The fact these attacks and blatant threats by Right-wing localists have been praised and retweeted by many feminists suggests it is not only anti-feminist individuals in the movement or people who were poorly informed about feminism who were involved in this kind of discursive violence. In other words, the shrinking of feminist discourse has come not only from the attacks of Right-wing localists, but also from feminists themselves.

\section{The Case of Wenshan Chen}

A second typical example is the case of Wenshan Chen's 2020 article on the Hong Kong protests advocating for feminist interventions that would 'maximise' the protest's 'overall positive utility' ( 並使其正面總體效益極大化). Her writing has a utilitarian tone that makes her sound more like the CEO of a 'feminist company' discussing the company's financing and product launch. From this perspective, it is not difficult to understand why Chen proposes that feminist activists who care about gender equality should not focus on challenging the patriarchal system embedded in the movement. Rather, she thinks feminists should ask whether this anti-ELAB movement has the potential to create a long-term impact on Hong Kong's patriarchal culture and social system (Chen 2020). From the perspective of a CEO, this is a 'reverse takeover' (借殼上市) strategy-that is, obtaining a controlling stake in an already listed company by injecting capital into it, allowing the assets of an otherwise unlisted company to be listed. However, since the controlling stake was not in the hands of the feminists but rather in the dominant voice of the movement, the expected reverse takeover did not happen. Rather, a 'reversed reverse takeover' (反向借殼) took place-that is, an intended takeover that was coopted by the other party. The anti-ELAB movement-originally seen by feminists as a tool to expand their own influence-has in turn captured the feminist agenda, making it a tool to help the movement expand its influence and enhance its perceived progressiveness.

By siding with the mainstream voices in the protest movement, feminists have gained nothing but their own defeat. This strategy of 'Left in form, Right in essence' feminists can deceive no-one but themselves. Why is it important for Left-leaning feminists and scholars to join forces with Rightwing localists even if they do not agree entirely with their ideologies and the strategies of the movement? Not only did they refuse to be critical of the Right's bordering practices, but they also took an active role at the forefront of discursive regulation to prove their loyalty to the people-still 
in the name of feminism and Leftist concerns. This strategic choice is related to their instrumentalist orientation.

\section{If Only We Would See: Connection in Support of Collusion}

Like feminists, Left-leaning scholars may also focus on retaining connections with mainstream protesters to preserve their remaining political capital and some degree of relevance and public trust in the context of the movement. The price they pay for this bargain could be high in terms of the loss of intellectual integrity, missed opportunities to provide critical feedback that could be useful to steer the decisions of the movement, and the temptation to sell out to Right-wing populism (Ho 2021). In other words, for both Leftist scholars and feminists, 'Left in form, Right in essence' may end up disguising rather than identifying hidden forces of oppression. Let us use as an example the case of Cho Man Kit, a lecturer in Gender Studies at the Chinese University of Hong Kong.

Minnie Li (2020e) reflected on the use of the word 'faggot', which was written in English on a protest poster to attack Hong Kong's Commissioner of Police. In response, Cho, a queer scholar and activist, wrote in a now deleted Facebook post: 'The use of discriminatory or implicitly derogatory terms to humiliate the police by protesters is ultimately a desire for justice, even if the process intentionally or unintentionally perpetuates and/ or reinforces derogatory discourses against minorities.' He went on to say:

We can completely disagree with such tactics that reinforce homophobic discourse, while at the same time trying to express our understanding in writing, to understand the desire for dignity and justice, as well as the anger and resentment that comes from being suppressed and persecuted for so long without a way out.
The hashtag ‘\#Connection_before_correction’ was added at the end of the post, which then was widely liked and shared on social media, including by many feminists. His slogan \#Connection_before_ correction also gained traction among many feminists who should have made use of the opportunity to talk about intersectional justice rather than condemning those who pointed out the problems. As a result of their emphasis on connections with the movement, they ended up excusing homophobia and justifying discrimination.

These feminists and Leftist scholars actively participated in different kinds of Right-wing bordering practices, especially in the monitoring and control of discursive space through knowledge production on social media or academic platforms. Their eagerness to please the mainstream voices of the movement eventually brought about their own defeat in the form of losing their relevance and impetus. The tragic aspect of this is that feminists now have nowhere to go, especially since they inflicted this situation on themselves when they helped to constrict the space for self-reflection needed for both self-transformation and the transformation of the movement.

\section{If Only We Would See: Coercive Solidarity and the Hierarchy of Victimhood}

Before we declared the defeat of feminism in Hong Kong, we had already penned articles in 2019 and 2020 about feminists selling their souls to the movement (Ho 2019a, 2019b). We documented the changes occurring within the movement and, particularly, the ways in which a collective identity-that of 'Hongkongers'-underpinned the intersubjective construction of a 'Hong Kong protesting self' defined antagonistically against its opponents and in identification with those constituted as 'true Hongkongers', the heroes of the struggle. How, and with whom, people identify can be highly emotive, expressing an ethic of solidarity that binds activists together as one. 
On top of 'coercive solidarity', we detected a 'hierarchy of suffering and victimhood' (Ho 2020; Kong et al. 2021) that was used to legitimise the differential extension of sympathy only to people who were seen as useful to the movement, while denying it to those who were deemed not usefulespecially those with certain identity markers, such as mainlanders, and those with independent or unconventional views who may not have been able or willing to say 'the right thing' to defend the movement. Denied recognition, these people's trials and suffering are as real as they are inaudible. We observe that there is no place for the ethics of care, except in relation to Yellow ribbons, especially those who have been 'valiant' (勇武)-that is, frontline protesters). The Blue ribbons and those perceived to be traitors to the movement are given no credence. Feminist values such as compassion for those with whom one disagrees and care for those in disadvantaged positionssuch as the disabled people who have been negatively affected by the protests (for instance, when streetlights were being vandalised)-are deemed irrelevant by feminists themselves. Needless to say, external enemies, especially the police, are those who deserve to die, such as the 37-year-old policewoman who drowned on duty as a marine officer during an anti-smuggling operation on 27 September 2021.

What the authors have experienced and observed is the collusion of feminists with the mechanism of coercive power within the movement. It is important to see this because coercive power is at the heart of the concept of the police. This internalised attitude of coercion ultimately constitutes a 'police system' in the general sense of a bottom-up approach. Feminists, because of their concern for various types of violence-such as domestic violence, sexual violence, and intimate-partner violence-are supposed to be sensitive to the operation of such power relations. Unfortunately, during the Hong Kong movement, they were also implicated in this 'policing from below'.

\section{If Only We Would See: Interconnected Histories}

The feminist ideal of unity amid diversity has given way to an intolerance of different opinions within the movement, of any criticism of movement tactics, and of any departure from an increasingly dominant localist, Sinophobic, and Right-leaning narrative. More progressive political positions have been disavowed and disallowed; alternative subjectivities either fail to emerge or are silenced. The political priority is preserving Hong Kong identity even if it means ruining Hong Kong, as in the case of advocating for a scorched-earth strategy ('If we burn, you burn with us!'). As researchers, we have been bothered by anti-Chinese sentiments, particularly the circulation of potentially inflammatory views that mainlanders (collectively and individually) are not only uncivilised, but also perverse. According to this ideology, mainland Chinese are the colonisers; Chinese colonialism is seen as the biggest evil, and mainlanders are invaders who have eroded Hong Kong society (Char 2020). Mainlanders, even if they are political dissidents themselves or supporters of the Hong Kong protest movement, become 'the enemy'. There is no space here for critical discussion of British colonialism.

Racial injustice and the gross inequalities within Hong Kong society are partly attributable to the city's colonial heritage. As Leo Goodstadt (2013) has argued, the mismanagement that has perpetuated poverty is both a legacy of British colonialism and the current administration's continuance of the colonial neglect of the local population. Elsewhere we have drawn attention to these issues as, in large part, a legacy of the 'interconnected histories' of China, Hong Kong, and the United Kingdom, as well as of their wider global connections (Jackson and Ho 2020: 47, ff.). Moreover, it is difficult to find space in which to talk about how British colonialism has shaped our mindsets, especially our understanding of liberal democracy, so we are aware of the danger of 'political beaconism'-that is, "the idealization of the "West" especially the United States as the "beacon of the light"' (Lin 2021: 93). These reflections should help us come up with a better diagnosis of the present. With 
more understanding of history, we may be able to open ourselves to learn from other anticolonial and anti-authoritarian intellectuals.

\section{If, and Only If, We Want to Live a Feminist Life under Authoritarian Rule}

In the post-National Security Law era in Hong Kong, there is limited appetite for feminist action in the form of new organisations or civil society groups, especially to express overt opposition to the government. There are other important forms of activism besides the obvious ones on the streets. For instance, Ahmed's (2017) 'Killjoy Survival Kit' includes several suggestions for how to slow the march of authoritarianism and enable feminism to survive. Feminists should embrace an ethics of care that will enable them to imagine other people's suffering as their own in the struggle against authoritarian rule (Ho 2020).

In our work, we have questioned our own hierarchy of suffering and victimhood and the importance of reviewing our bordering practices. Some strategies for protecting our identity as Hongkongers include drawing boundaries between the self and the Other-us and them, in the populist narrative. However, these are cruel to mainlanders and to disadvantaged communities, as well as to ourselves. What began as an assertion of dignity, a recovery from exclusion and denigration, and a demand for representation has led to a hardening of oppressive and exclusionary boundaries. As we have all been part of the bordering practices involved, we must examine our ways of drawing boundaries and allow the subordinated identities to find a place from which to speak. When Hongkonger identity is all that matters, other politically salient identities, such as gender, class, ethnicity, and so on, are played down. If preserving a particular version of Hong Kong is deemed a priority, we will be blinded to all sorts of inequalities in our society. Has queer theory not taught us to transcend identity politics?
Let us keep writing. We should not relinquish free speech and surrender the public domain too easily. We can still write to journals and whoever else can publish our works. This article is another attempt to initiate a dialogue among ourselves. As Ahmed (2000) has suggested, feminist theorising (and activism) is about questioning existing categories and allowing internal dissent. Everything we have done so far has to be seriously reconsidered. If we take off our 'Yellow-coloured glasses', hopefully, we will see things we could not see before. If we cannot talk about these issues among ourselves, the regime really has won.

The authors would like to thank Dr Clifton Emery and Jimmy Cheng for suggesting a diagram to explain the structure of the Hong Kong protest movement. We also thank Professor Stevi Jackson and Dr Jon Solomon for commenting on and editing drafts of the article. 
This text is taken from Made in China Journal: Volume 6, Issue 3, 2021, edited by Ivan Franceschini, Nicholas Loubere and Shui-yin Sharon Yam, published 2022 by ANU Press, The Australian National University, Canberra, Australia.

doi.org/10.22459/MIC.06.03.2021.10 